\title{
Exclusions for resolving urban badger damage problems: outcomes and consequences
}

\author{
Alastair I Ward Corresp., 1, 2 , Jason K Finney ${ }^{2}$, Sarah E Beatham ${ }^{2}$ ， Richard J Delahay ${ }^{3}$ ， Peter A Robertson ${ }^{2,4}$, \\ David P Cowan ${ }^{2}$ \\ ${ }^{1}$ School of Environmental Sciences, University of Hull, Hull, United Kingdom \\ 2 National Wildlife Management Centre, Animal and Plant Health Agency, York, North Yorkshire, United Kingdom \\ 3 National Wildlife Management Centre, Animal and Plant Health Agency, Woodchester Park, Gloucestershire, United Kingdom \\ 4 School of Biology, Newcastle University, Newcastle-upon-Tyne, United Kingdom \\ Corresponding Author: Alastair I Ward \\ Email address: a.i.ward@hull.ac.uk
}

Increasing urbanisation and growth of many wild animal populations can result in a greater frequency of human-wildlife conflicts. However, traditional lethal methods of wildlife control are becoming less favoured than non-lethal approaches, particularly when problems involve charismatic species in urban areas. Eurasian badgers (Meles meles) excavate subterranean burrow systems (setts), which can become large and complex. Larger setts within which breeding takes place and that are in constant use are known as main setts. Smaller, less frequently occupied setts may also exist within the social group's range. When setts are excavated in urban environments they can undermine built structures and can limit or prevent safe use of the area by people. The most common approach to resolving these problems in the UK is to exclude badgers from the problem sett, but exclusions suffer a variable success rate. We studied 32 lawful cases of badger exclusions using one-way gates throughout England to evaluate conditions under which attempts to exclude badgers from their setts in urban environments were successful. We aimed to identify ways of modifying practices to improve the chances of success. Twenty of the 32 exclusion attempts were successful, but success was significantly less likely if a main sett was to be excluded in comparison with another type of sett and if vegetation was not completely removed from the sett surface prior to exclusion attempts. We recommend that during exclusions all vegetation is removed from the site, regardless of what type of sett is involved, and that successful exclusion of badgers from a main sett might require substantially more effort than other types of sett. 
1 Exclusions for resolving urban badger damage problems: outcomes and consequences

Alastair I. Warda,b, Jason K. Finney ${ }^{b}$, Sarah E. Beatham ${ }^{b}$, Richard J. Delahayc, Peter A. Robertson ${ }^{b, d}$, David P. Cowan ${ }^{b}$

aSchool of Environmental Sciences, University of Hull, Cottingham Road, Hull, United Kingdom

bNational Wildlife Management Centre, Animal and Plant Health Agency, Sand Hutton, York, North Yorkshire, United Kingdom

11 cNational Wildlife Management Centre, Animal and Plant Health Agency, Woodchester

12 Park, Gloucestershire, United Kingdom

13 dSchool of Biology, Newcastle University, Newcastle upon Tyne, United Kingdom

14

15 Corresponding author

16 E-mail: a.i.ward@hull.ac.uk

17

18 


\section{Abstract}

20 Increasing urbanisation and growth of many wild animal populations can result in a 21 greater frequency of human-wildlife conflicts. However, traditional lethal methods of 22 wildlife control are becoming less favoured than non-lethal approaches, particularly 23 when problems involve charismatic species in urban areas. Eurasian badgers (Meles meles) excavate subterranean burrow systems (setts), which can become large and complex. Larger setts within which breeding takes place and that are in constant use are known as main setts. Smaller, less frequently occupied setts may also exist within the social group's range. When setts are excavated in urban environments they can undermine built structures and can limit or prevent safe use of the area by people. The most common approach to resolving these problems in the UK is to exclude badgers from the problem sett, but exclusions suffer a variable success rate.

We studied 32 lawful cases of badger exclusions using one-way gates throughout England to evaluate conditions under which attempts to exclude badgers from their setts in urban environments were successful. We aimed to identify ways of modifying practices to improve the chances of success. Twenty of the 32 exclusion attempts were successful, but success was significantly less likely if a main sett was involved and if vegetation was not completely removed from the sett surface prior to exclusion attempts.

We recommend that during exclusions all vegetation is removed from the site, regardless of what type of sett is involved, and that successful exclusion of badgers from a main sett might require substantially more effort than other types of sett. 
44

45

46

47

48

49

50

51

52

53

54

55

56

57

58

59

60

61

62

63

64

65

66

67

68

69

70

71

72

73

74

75

76

77

78

79

80

81

82

83

84

85

86

87

88

89

\section{Introduction}

Landscapes are becoming increasingly urbanised throughout the world (United Nations, 2003), threatening traditional wildlife habitat. In contrast, protective wildlife legislation has, most likely contributed to the growth of some wildlife populations (Heydon et al. 2010). Together, these two factors are likely to drive an increase in the frequency of interactions and conflicts between humans and wildlife (DeStefano and DeGraaf 2003; Soulsbury and White 2015; White and Ward 2010). Such conflicts can be extremely costly, for example, wildlife damage and its control in urban areas of the USA has cost an estimated US $\$ 8.6$ billion per year (Conover 2001). Nevertheless, growing public antipathy towards lethal control of wild animals (Littin and Mellor 2005; White et al. 2003) and ethical obligations regarding animal welfare require that we include the development of further humane and non-lethal techniques for intervention. Moreover, interventions need to be sustainable, such that they effectively and permanently resolve problems rather than simply delaying or moving them elsewhere (Davison et al. 2011), whilst also allowing the persistence of viable wildlife populations in rapidly urbanising landscapes.

Many meso-carnivores have become well-adapted to an existence in urban, suburban and peri-urban environments (hereafter referred to collectively as urban environments), including foxes (Vulpes vulpes; Harris and Smith 1987) and stone martens (Martes foina; Herr et al. 2010) in Europe, and racoons (Procyon lotor; Prange et al. 2003) in North America. In particular, Eurasian badgers (Meles meles), are widespread and increasingly abundant in rural and urban environments across much of Eurasia (Roper 2010). They have become well habituated to urban areas (e.g. England: Davison et al. 2008, Norway: Bjerke et al. 2003; Japan: Tanaka et al. 2002) and their presence is often welcomed, and sometimes actively encouraged, by householders (Bjerke et al. 2003). However, their presence can result in problems such as damage to gardens and buildings, mainly through sett (subterranean burrow) excavation. In England the Protection of Badgers Act 1992 makes it an offence to interfere with any badger or their sett without a licence from the statutory authority (Natural England). Of the 500-600 applications per year for such licences received by Natural England, an increasing proportion has arisen in urban areas in some regions in recent years. For example, during 1994 to 1996 approximately 15 to $20 \%$ of licence applications came from urban areas of southern and eastern England, rising to approximately 25 to $40 \%$ during 2002 to 2004 (Delahay et al. 2009). Licence applications can be submitted by the landowner or someone appointed by them and any subsequent management action permitted by the licence can be undertaken by the licensee.

The potential options for managing problems caused by badger sett construction currently include doing nothing, exclusion of badgers from the problem sett, translocation or localised culling. Doing nothing may not be an acceptable option from the licence applicants' perspective and is generally only a realistic option where there is no clear evidence of serious damage. Translocation is unlikely to constitute a reliable or desirable solution in many cases since it is expensive (Beringer et al. 2002), has a questionable success rate (Griffith et al. 1989) and risks causing economic and ecological problems by, for example, impacting on local fauna and flora and spreading disease to new areas 
90 (Craven et al. 1998, Massei et al. 2010). Proposals to cull badgers can be very unpopular

91

92

93

94

95

96

97

98

99

100

101

102

103

104

105

106

107

108

109

110

111

112

113

114

115

116

117

118

119

120

121

122

123

124

125

126

127

128

129

130

131

132

133

134

135 with the public. The most common approach currently used to resolve problems caused by urban badgers is to exclude them from their setts by fitting gates that open outwards but not inwards over every entrance hole, and then to destroy the sett structure once the badgers have been successfully excluded (Delahay et al. 2009). Advice on exclusion methods is currently based on expert opinion (e.g. https://www.gov.uk/guidance/badgerssurveys-and-mitigation-for-development-projects accessed 11 January 2016). Exclusion may include measures to facilitate fitting of one-way gates, such as vegetation removal, and to prevent badgers from excavating new holes at the site, for example by laying a covering of heavy-gauge galvanized chain link fencing mesh over the ground surrounding the sett. Under some circumstances, such as when badgers are to be excluded from only part of the sett, or whether doubt remains as to whether all badgers have been excluded, exclusion has been followed by careful and systematic excavation of the sett to ensure that all badgers have been successfully evicted. Such works are the responsibility of the licensee or their agent and typically cost GB£5,000-£10,000 for the exclusion of badgers from a modest-sized sett on residential property (Davison et al. 2011).

Many hundreds of sett exclusions are undertaken each year in England alone (Delahay et al. 2009), yet evidence of the effectiveness of different exclusion methods is largely lacking. Following the review of reports from those licensed to undertake exclusions, Delahay et al. (2009) noted a low success rate for those involving main setts in urban environments. However, sett management factors that influence the success or failure of attempts to exclude badgers have yet to be empirically demonstrated.

We aimed to evaluate conditions under which licensed attempts to exclude badgers from their setts in urban environments were successful in order to identify ways of modifying practices to improve the chances of success. Improved practices may help address the apparently low success rate of exclusions in urban England, but they may also offer options for the management of problems associated with other burrowing mammals where lethal control is a least-preferred solution. Our objective was to evaluate the factors likely to determine the outcome of licensed badger exclusions from setts.

\section{Methods}

The study proceeded with the approval of the Central Science Laboratory's (now part of the Animal and Plant Health Agency) Ethical Review panel and was conducted under licence 20072352 from Natural England. The broader project within which this study was conducted required the capture and marking of wild badgers under general anaesthesia (de Leeuw et al. 2004), which was undertaken under licences PPL 60/3351 and PIL $60 / 9302$ from the Home Office.

For the purpose of the present study we collated information from Natural England Wildlife Advisors on 39 of 45 applications for licensed sett exclusions in urban, suburban and periurban (albeit within the built environment) areas throughout England during the period May 2004 to October 2010. Of these, 32 were included because it was clear that exclusion 
136

137

138

139

140

141

142

143

144

145

146

147

148

149

150

151

152

153

154

155

156

157

158

159

160

161

162

163

164

165

166

167

168

169

170

171

172

173

174

175

176

177

178

179

180

attempts were going to proceed that year; a small proportion of applications do not result in action being taken against the sett. In each case at least two visits were undertaken, the first to survey badger activity at the sett prior to the commencement of licensed activity and the second to assess exclusion methods once they had been put in place.

\subsection{Sett surveys}

A full sett survey was conducted at each site, following a procedure adapted from Wilson et al. (2003). At each sett the number of entrance holes was counted and each hole was scored for the condition of the tunnel floor $(0=$ obstructed, $1=$ loose, $2=$ compacted $)$, the condition of the tunnel walls $(0=$ unpolished, $2=$ polished $)$, the presence of footprints in the tunnel or at the entrance $(0=$ absent, $3=$ present $)$, the presence of recently excavated soil on the spoil heap $(0=$ absent, $3=$ present $)$, and the presence of fresh bedding material on the spoil heap $(0=$ absent, $3=$ present $)$. The scores for each category were summed to produce an activity score for the sett, which broadly correlates with badger abundance at the sett (Wilson et al. 2003). The sett was also described as a main sett or other type of sett based on its physical characteristics. Main setts are those that are inhabited all year round, are used for breeding and are the focal point of the badger social group. Other types of setts include outlier setts, which are used less frequently, so are not permanently occupied, and may not be used by every member of the social group (Neil and Cheeseman 1996). During the present study, main setts were assigned on the basis of their relatively large size, the presence of several active holes with sizeable spoil heaps or other signs of significant activity and if obvious badger runs were observed radiating from the sett.

\subsection{Exclusion surveys}

During typical sett exclusions one-way gates are installed at entrance holes and activity is monitored for at least 21 days by placing small sticks just inside the gate, which are disturbed if a badger exits past them. When disturbance of the sticks or other evidence of activity within the sett ceases, it is considered to be unoccupied. When no signs are detected to indicate that badgers have gained entry to the sett over a period of 21 consecutive days, this is taken as evidence that badgers are no longer occupying the sett (https://www.gov.uk/guidance/badgers-surveys-and-mitigation-for-developmentprojects accessed 11 January 2016) and the structure may be permanently sealed or destroyed.

When the licensee confirmed that badger activity at the sett had been absent for 21 to 31 days (i.e. the 21 day exclusion period, plus up to 10 days of leeway to account for breaches back into the sett and subsequent remedy), we scored this as a successful exclusion. If the licensee confirmed that badger activity had not been prevented at the sett within the 31 days we scored this as a failure. These assessments risked overestimating the failure rate, since improvements to exclusion practices as the exclusion progressed beyond 31 days, which we did not assess, could have resulted in a 
181 successful exclusion. Nevertheless, failure to exclude badgers within 31 days implies

182

183

184

185

186

187

188

189

190

191

192

193

194

195

196

197

198

199

200

201

202

203

204

205

206

207

208

209

210

211

212

213

214

215

216

217

218

219

220

221

222

223

224

225

226 that the measures used initially were inadequate to achieve exclusion within that period.

We re-examined setts approximately 31 days after implementation of exclusion measures. The licensee reported whether the exclusion was intended to be complete (i.e. targeting the whole sett) or partial (i.e. targeting part of the sett). A partial exclusion might be attempted where the licensee does not have access to every entrance hole, such as if some holes are present on the property of an uncooperative neighbour. We recorded the number of active and inactive entrance holes, the number of holes fitted with one-way gates or otherwise blocked, removal of surface vegetation, the proportion of the ground surface that needed to be covered with chain link that was covered with chain link (based on our opinion of the area of the property susceptible to badger digging and that could allow re-entry to the sett), and information on any other exclusion methods that may have been used, such as hard core-filled trenching around the site or excavation of the structure following gating. The presence and number of alternative setts used within the social group's range was identified for each case during a programme of tracking of badgers fitted with radio telemetry collars (not reported here). Collared badgers were tracked each day for two weeks prior to exclusion and two weeks during exclusions.

\subsection{Data analysis}

In order to predict the likelihood of success, we modelled exclusion outcomes (success or failure) using a generalized linear model procedure, with a binomial distribution and logit link function. Variables entered into the full model to attempt to explain variation in success were: Exclusion type (1= partial, $2=$ complete), Sett type (1= main, 2 = other), Sett activity (score), Holes $(1=$ all holes gated, $2=$ fewer than all holes gated), Vegetation removal $(1=$ nil, $2=$ partial removal of vegetation, $3=$ complete removal of vegetation), Other setts $(1=$ no other setts identified in range, $2=$ one or more alternative setts identified in range), and Chain link ( $1=$ incomplete coverage with chain link, 2 = complete coverage). Excavation of the sett following gating was not included as a factor in the full model since it was undertaken infrequently and was invariable i.e. all excavations were successful at excluding badgers. For this analysis we excluded two cases, which were re-attempts at exclusion at sites where similar efforts had failed during the previous season. However, we included two cases that were re-attempts at exclusion following an interlude of more than one year because the contractors employed to undertake the exclusion and the methods used varied between successive attempts. Prior to derivation of the full model, we sought to control collinearity by removing one variable from each pair of explanatory variables that were strongly correlated with one another $\left(r_{s}\right.$ $<0.6, P<0.05)$. The remaining variables were all then entered into the model simultaneously. The least significant variable was removed and the analysis was re-run. Once only significant variables remained within the model we attempted to sequentially fit all two-way interactions to form a suite of different candidate models. The model with only significant variables and their interactions, and with the lowest Akaike's Information Criterion score corrected for small sample size (AICc) was selected as the final model (Burnham and Anderson 2002). 
Model fit was assessed by standard validation procedures (residuals checking, Cook's distance), and by fitting the data from the cases into the model in order to calculate the number of times that the model correctly predicted the exclusion outcome. All statistical analyses were undertaken using SPSS 17.0.0 (IBM, New York).

\section{Results}

\subsection{Sett surveys}

Of the 45 sett exclusion licence applications referred to us, 39 were investigated for inclusion in the study. The 32 cases studied represented 30 sites; four cases were from two sites, each studied during two separate years. Among the 30 sites 27 were suburban, mostly in private gardens adjacent to housing, and three were peri-urban, one of which was a churchyard, the other two being private gardens adjacent to housing but bordering rural landscapes. Main setts were the focus of 20 of the 32 cases (Table 1). Setts were spread over more than one property in 10 cases, one of which involved four properties.

Some clustering of cases was observed in space and time. Excluding the repeat cases, five were in the south east (East Sussex; one in 2005 and two each in 2006 and 2007), seven in the midlands (East Midlands: one in 2004, West Midlands; one in 2006, two in 2007 and three in 2008), five in the east (Essex; one in 2004, three in 2005 and one in 2007), four in the north west (Cheshire; one each in 2006, 2007, 2008 and 2010), two in the south (Hampshire; 2008 and 2009), two in Greater London (2006 and 2007), two in the west (Gloucestershire; one each in 2008 and 2009) two in the North East (South Yorkshire and Northumberland, both in 2009) and one in Oxfordshire (2008) (Figure 1). However, in only one instance we identified a direct association between two consecutive cases. In this instance, badgers marked at a sett in Essex, from which they were excluded, were trapped the following year at another sett on a nearby property. 


\subsection{Exclusion surveys}

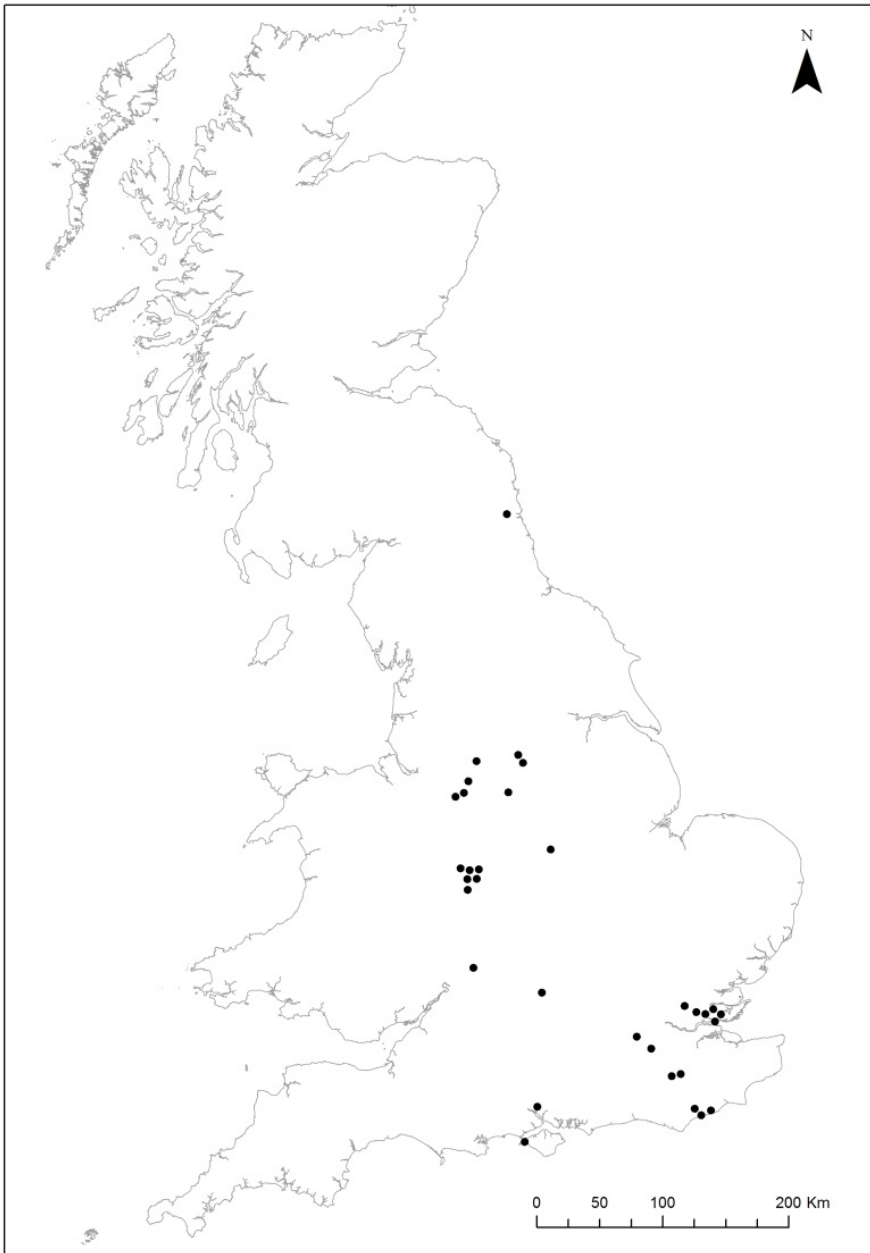

Figure 1. The distribution of 32 licensed sett exclusions studied. Plotted locations may be $1 \mathrm{~km}$ from the study site locations to allow discrimination of clustered cases. Of the 32 attempts to exclude badgers from setts, 20 were successful and 12 were
unsuccessful (Table 1$)$ based on the subsequent presence or absence, respectively, of
signs of badger activity for at least 21 consecutive days.
No explanatory variables were collinear, but some were weakly/moderately
correlated. For example, Chain link was negatively correlated with Excavation $\left(r_{s}=-0.455\right.$,
$n=30, P=0.012)$, which is consistent with licensees resorting to excavation after
deploying inadequate chain link and subsequent exclusion failure. However, since no
unsuccessful cases involved excavation, it was not possible to include this variable in
further analyses.
The full model was not significantly different from the intercept only model $\left(x^{2}=\right.$
12.56, df $=8, P=0.128$, and AICc $=55.96)$. After exclusion of non-significant terms 
278 (factors, variables and their two-way interactions), only two factors remained. Among 279 these Vegetation removal was significant for level 0 (no vegetation removal versus level 2802 complete removal), but not for level 1 (partial removal versus complete removal, $P=$ $2810.083, \mathrm{AICC}=19.65$ ). Consequently, we combined categories within Vegetation removal 282 ( $1=$ incomplete removal, $2=$ complete removal $)$ and re-ran the analysis. The final model 283 was significantly different from the intercept only model $\left(X^{2}=10.66, \mathrm{df}=2, P=0.005\right.$ and 284 AlCc = 14.16), with two factors remaining (Table 2). Running the same analysis as a 285 binary logistic regression revealed the moderate predictive power of the model (Cox and 286 Snell $r^{2}=0.299$, Nagelkerke $r^{2}=0.404$ ), correctly predicting the outcome of cases on $28780 \%$ of occasions (correct prediction of success $=83 \%$, correct prediction of failure $=$ $28875 \%)$.

289

290

291

292

293

294

295

296

Table 1. Characteristics of successful and unsuccessful outcomes in 32 cases of attempted badger exclusion. Figures given are frequency by category, or the mean (and standard deviation).

\begin{tabular}{|c|c|c|c|}
\hline \multicolumn{2}{|c|}{ Characteristic } & \multirow{3}{*}{$\begin{array}{r}\text { Successful } \\
15 \\
5\end{array}$} & \multirow{3}{*}{$\begin{array}{r}\text { Unsuccessful } \\
10 \\
2\end{array}$} \\
\hline Exclusion type: & Complete & & \\
\hline & Partial & & \\
\hline \multirow[t]{2}{*}{ Sett type: } & Main & 10 & 10 \\
\hline & Other & 10 & 2 \\
\hline \multicolumn{2}{|c|}{ Vegetation removal: Nil } & 8 & 6 \\
\hline & Partial & 7 & 5 \\
\hline & Complete & 5 & 1 \\
\hline \multirow[t]{2}{*}{ Excavation: } & No & 16 & 12 \\
\hline & Yes & 4 & 0 \\
\hline \multicolumn{2}{|c|}{ Sett activity score (mean and SD) } & $30.8(22.7)$ & $52.1(42.2)$ \\
\hline \multicolumn{2}{|c|}{ Proportions of holes gated (mean and SD) } & $0.88(0.31)$ & $0.89(0.29)$ \\
\hline \multicolumn{2}{|c|}{ Proportion of chain link (mean and SD) } & $0.49(0.44)$ & $0.53(0.40)$ \\
\hline \multicolumn{2}{|c|}{ Number of alternative setts (mean and SD) } & $1.95(1.23)$ & $1.33(0.89)$ \\
\hline
\end{tabular}

Table 2. Final model to explain the failure of efforts to exclude badgers from their setts.

\begin{tabular}{lrrcccc}
\hline \multicolumn{1}{c}{ Variable } & $\boldsymbol{\beta}$ & SE & $\begin{array}{l}\text { Odds } \\
\text { ratio }\end{array}$ & Wald & df & $\boldsymbol{P}$ \\
\hline (Intercept) & -4.32 & 1.50 & 0.013 & 8.31 & 1 & 0.004 \\
Sett type (main) & 2.71 & 1.02 & 15.00 & 7.02 & 1 & 0.008 \\
Vegetation removal (incomplete) & 2.71 & 1.28 & 15.00 & 4.46 & 1 & 0.035 \\
\hline
\end{tabular}


298 Sett exclusion using one-way gates was 15 times more likely to fail if a main sett was

299 involved (Odds ratio in Table 2) than if it were some other type of sett and 15 times

300 more likely to fail if all vegetation was not removed than if only some or no vegetation

301 was removed.

302

303

\section{Discussion}

304

305

306

307

308

309

310

311

312

313

314

315

316

317

318

319

320

321

322

323

324

325

326

327

328

329

330

331

332

333

334

335

336

337

338

339

340

341

342
A high proportion of applications to Natural England to exclude badgers from their setts in urban areas involve main setts (Delahay et al., 2009). Main setts are limiting resources for badgers; in rural environments they tend to be located on slopes of freedraining soils (Kruuk 1978). Moreover, they are intensely defended as a key breeding resource (Doncaster and Woodroffe 1993). This may explain why the presence of alternative setts within a social group's range, which are typically fewer in urban areas in comparison with rural areas (Davison et al. 2008), was not significantly associated with the success or failure of attempts to exclude badgers in this study: badgers sought to remain in the main sett irrespective of alternative sett availability. However, our sample size was small and factors and variables tested were not equitably balanced between successful and unsuccessful exclusion attempts. It is possible that a larger and better balanced study than this might provide greater clarity on the importance of alternative sett availability for the successful exclusion of badgers.

In the present study main setts constituted the majority of problem cases investigated and it is perhaps no surprise that attempts to exclude badgers from them were far less frequently successful than exclusions from other types of sett. During our study badgers were successfully excluded from $50 \%$ of main setts, which is consistent with the $35 \%$ reported by Delahay et al. (2009). Sett exclusion using one-way gates was more likely to fail at a main sett than at some other type of sett and more likely to fail if all vegetation was not removed. Moreover, the failure of exclusion attempts at sites at which vegetation was completely removed was almost completely explained by the presence of a main sett, and failure at sites with other types of setts was almost completely explained by the failure to remove all vegetation. Exclusion of badgers from a main sett had an even greater likelihood of failure if all vegetation was not removed from the site. However, the significance of Vegetation removal became more evident once this factor was grouped from three into two categories. Further support for the importance of vegetation removal for the successful exclusion of badgers from their setts would require a larger sample size that was better balanced between success and failure and levels of vegetation removal.

Vegetation removal might act in two ways: it creates disturbance and removes cover from the sett, which may make the site unattractive to badgers (Jepsen et al., 2005; Remonti et al., 2006; Smal, 1995; Thornton, 1988; Wright et al., 2000), and may also facilitate the deployment of chain link over the sett surface. A further field experiment would be required to separate the mechanisms driving the effect of vegetation removal on badger behaviour. Complete removal of vegetation at the scale of the typical English suburban garden (circa $150 \mathrm{~m}^{2}$ ) is unlikely to cause significant long term environmental impacts. 
Chain link was not significantly associated with the success/failure of sett exclusion attempts, probably because in the examples we studied it was rarely deployed securely. Indeed, in many cases where it was deployed, we believe (but have no empirical data in support) that failure to cover a sufficient area, failure to adequately secure joins between sections of chain link or to bury the periphery into a trench, resulted in badgers re-gaining access to the sett at these weak points. Our observations also lead us to believe that scrupulous deployment of chain link was more important for successful exclusion of main setts than for other sett types. However, to confirm or refute these hypotheses, further observation of cases or field experimentation are required where chain link is deployed securely and insecurely.

In three cases where badgers were not successfully excluded from setts, postgating excavation was undertaken following failure of the one-way gates over a period of at least 21 days. In all three cases, the excavation was successful in removing the badgers. This practice resulted in the destruction of the sett, and hence was particularly likely to succeed, although our sample size was too small to allow general conclusions. Moreover, while excavation may be effective, the cases observed during this study required substantial effort, in terms of human resources and the skilful capture of badgers remaining in the sett at the time of excavation.

A further challenge associated with main setts in urban areas is that they may often spread over multiple properties in spite of urban main setts typically being smaller than those in rural areas (Davison et al. 2008). One third of all cases studied involved a sett with entrance holes on more than one property. Anecdotally, a high level of cooperation between affected neighbours did seem to benefit the success of exclusion efforts in these cases (Supplementary material 1); co-operation across affected ownership boundaries is required for successful management of wildlife damage (White and Ward 2010).

Badger home ranges in urban England tend to be much smaller than those of their rural counterparts (Davison et al. 2008) and movements between social groups, while frequent, may cover shorter distances (Huck et al. 2008). Consequently, factors that influence space use and responses to exclusion attempts are likely mainly to exist within the vicinity of the sett. While it is not possible to discount the importance of un-measured factors in determining the success of exclusion attempts, the most important ones are likely to have been included in the present study.

Measures that might be expected to improve the probability of success when attempting to exclude badgers from a sett include negative stimuli, such as deterrents, and provision of additional resources, such as the construction of an artificial sett. However, badgers have been observed to rapidly habituate to ultrasonic and physical deterrents, rendering them ineffective (Ward et al. 2008). Also, as badgers typically have access to multiple setts within their social group range, even in urban environments (Davison et al. 2008), it is unclear whether provision of an additional artificial structure at a location not selected by badgers would enhance the likelihood that they would leave their main sett. Moreover, the internal characteristics of artificial setts may be different to 
388 those of natural setts (Kaneko et al. 2013), making their attractiveness relative to natural 389 setts uncertain.

390

391

392

393

394

395

396

397

398

399

400

401

402

403

404

405

406

407

408

409

410

411

412

413

414

415

416

417

418

419

420

421

422

423

424

425

426

427

428

429

430

431

432

Davison et al. (2011) did not find temporal or spatial clustering of licence applications, and the distribution of cases that we observed is generally consistent with this. Nevertheless, we did observe sequential causation on one occasion, whereby badgers excluded from a sett on one property were the subject of a licence application pertaining to a nearby property. Therefore, we conclude that while successful exclusion of badgers from their setts always moves the badgers to an alternative sett, usually on another property, shifting of the problem between properties, may be infrequent. That is, the presence of badgers on urban properties does not always constitute a problem.

\section{Conclusion}

The licensed exclusion of badgers from a problem sett can be an effective means of resolving damage problems. However, successful exclusion depends on a variety of factors, including the type of sett involved and the quality and quantity of the effort invested in excluding badgers from the sett. Licence applicants should be advised that to maximise the chances of successfully excluding badgers all vegetation should be removed from the site, regardless of what type of sett is involved, and that successful exclusion of badgers from a main sett might require substantially more effort than other types of sett.

As urban environments expand and the potential for human-badger conflicts grows throughout Britain, so the need to develop and refine best practice techniques to managing damage problems increases. Further investigation of the behaviour and ecology of urban-dwelling wildlife species that cause problems for humans, and systematic investigation of the effectiveness of existing and novel approaches are required in order to underpin the development of humane, sustainable, environmentally benign, non-lethal solutions.

\section{Acknowledgements}

We are grateful to all the Natural England Wildlife Advisors who supplied case information and accompanied us on site visits, and to the homeowners and licensees who granted permission for us to study their cases. We thank Stéphane Pietravalle and Rebecca Callaby for advice on statistical analysis. We are also grateful to Richard Brand-Hardy, Ashley Matthews, Matt Heydon, Elaine Gill, Rodney Calvert, Simon Mackown, Gary Witmer three anonymous Defra reviewers and two anonymous journal reviewers for helpful comments on drafts of this manuscript.

\section{References}

Beringer, J., Demand, J.A., Sartwell, J., Wallendorf, M. \& Mange, R. (2002) Efficacy of translocation to control urban deer in Missouri: Costs, efficiency, and outcome. Wildlife Society Bulletin, 30, 767-774. 
433 Bjerke, T., Østdahl, T. \& Klimer, J. (2003) Attitudes and activities related to urban wildlife: Pet owners and non-owners. Anthrozoos, 16, 252-262.

Burnham K. P. \& Anderson D. R. (2002) Model selection and multimodel inference. A practical information-thoretic approach. Springer-Verlag, New York.

Conover, M. R. (2001). 'Resolving human-wildlife conflicts: the science of wildlife damage management.' (CRC Press: Boca Raton, FL.)

Craven, S., Barnes, T. \& Kania, G. (1998) Toward a professional position on the translocation of problem wildlife. Wildlife Society Bulletin, 26, 171-177.

Davison J., Huck, M., Delahay, R. J. \& Roper, T. J. (2008) Urban badger setts: characteristics, patterns of use and management implications. Journal of Zoology, 275, 190-200.

Davison, J., Roper, T. J., Wilson, C. J., Heydon, M. J. \& Delahay, R. J. (2011) Assessing spatiotemporal associations in the occurrence of badger-human conflict in England. European Journal of Wildlife Research, 57, 67-76.

Delahay, R. J., Davison, J., Poole, D. W., Matthews, A. J., Wilson, C. J., Heydon, M. J. \& Roper, T. J. (2009) Managing conflict between humans and wildlife: trends in licensed operations to resolve problems with badgers Meles meles in England. Mammal Review, 39, 53-66.

De Leeuw A.N.S., Forrester G.J., Spyvee P.D., Brash M.G.I. and Delahay R.J. (2004) Experimental comparison of ketamine with a combination ketamine, butorphanol and medetomidine for general anaesthesia of the Eurasian badger (Meles meles L.). The Veterinary Journal, 167, 186-193.

DeStefano S. and DeGraaf R.M. (2003) Exploring the ecology of suburban wildlife. Frontiers in Ecology and the Environment, 1, 95-101.

Doncaster C. P. and Woodroffe R. (1993) Den site can determine shape and size of badger territories: implications for group living. Oikos, 66, 88-93.

Griffith, B., Scott,J.M., Carpenter, J.W. \& Reed, C. (1989) Translocation as a species conservation tool - status and strategy. Science, 245, 477-480.

Harris, S. \& Smith, G. C. (1987) Demography of two urban fox (Vulpes vulpes) populations. Journal of Applied Ecology, 24,75-86.

Herr, J., Schley, L., Engel, E. \& Roper, T. J. (2010) Den preferences and denning behavior in urban stone martens (Martes foina). Mammalian Biology, 75, 138145.

Heydon, M. J., Wilson, C. J., and Tew, T. (2010). Wildlife conflict resolution: a review of problems, solutions and regulation in England. Wildlife Research, 37, 731-748.

Huck, M., Frantz, A. C., Dawson, D. A., Burke, T. and Roper, T. J. (2008) Low genetic variability, female-biased dispersal and high movement rates in an urban population of Eurasian badgers Meles meles. Journal of Animal Ecology, 77, 905-915.

Jepsen, J. U., Madsen, A. B., Karlsson, M. \& Groth, D. (2005) Predicting distribution and density of european badger (Meles meles) setts in Denmark. Biodiversity and Conservation, 14, 3235-3253.

Kaneko, Y., Newman, C., Buesching, C. D. and Macdonald, D. W. (2013) Variations in badger (Meles meles) sett microclimate: differential cub survival between main and subsidiary setts, with implications for artificial sett construction. International Journal of Ecology 2010, Article ID 859586, 10 pages, doi:10.1155/2010/859586 
479

480

481

482

483

484

485

486

487

488

489

490

491

492

493

494

495

496

497

498

499

500

501

502

503

504

505

506

507

508

509

510

511

512

513

514

515

516

517

518

519

520

521
Kruuk H. (1978) Spatial organization and territorial behaviour of the European badger Meles meles. Journal of Zoology, 184, 1-19.

Littin, K. E., and Mellor, D. J. (2005). Strategic animal welfare issues: ethical and animal welfare issues arising from the killing of wildlife for disease control and environmental reasons. Revue Scientifique et Technique (International Office of Epizootics), 24, 767-782.

Massei Smith G., Quy R.J., Gurney J. \& Cowan D.P (2010) Can translocations be used to mitigate human-wildlife conflicts? Wildlife Research, 37, 428-439

Neil, E. and Cheeseman, C (1996) Badgers. T. and A. D. Poyser Ltd., London.

Prange, S., Gehrt, S. D. \& Wiggers, E. P. (2003) Demographic factors contributing to high racoon densities in urban landscapes. Journal of Wildlife Management, 67, 324-333.

Remonti, L., Balestrieri, A. \& Prigioni, C. (2006) Factors determining badger Meles meles sett location in agricultural ecosystems of NW Italy. Folia Zoologica, 55, 19-27.

Roper, T. J. (2010) Badger. HarperCollins Publishers, London.

Smal, C. (1995). The Badger and habitat survey of Ireland. In. National Parks \& Wildlife Service, \& The Department of Agriculture, Food \& Forestry, Dublin.

Soulsbury, C.D. and White, P.C.L. (2015) Human-wildlife interactions in urban areas: a review of conflicts, benefits and opportunities. Wildlife Research, 42, 541-553.

Tanaka, H., Yamanaka, A. \& Katsuhiko, A. (2002) Spatial distribution and sett use by the Japanese badger, Meles meles anakuma. Mammal Study, 27, 15-22.

Thornton, P.S. (1988) Density and distribution of badgers in south-west England - a predictive model. Mammal Review, 18, 11-23.

United Nations. (2003). World Urbanization Projects - The 2003 Revision. In. United Nations Secretariat, Population Division, New York.

Ward, A. I., Pietravalle, S., Cowan, D. P. and Delahay, R. J. (2008) Deterrent or dinner bell? Alteration of badger activity and feeding at baited plots using ultrasonic and water jet devices. Applied Animal Behaviour Science, 115, 221-232.

White, P. C. L., Newton-Cross, G., Moberly, R. L., Smart, J. C. K., Baker, P. J., and Harris, S. (2003). The current and future management of wild mammals hunted with dogs in England and Wales. Journal of Environmental Management, 67, 187-197.

White, P.C.L. and Ward, A. I. (2010) Interdisciplinary approaches for the management of existing and emerging human-wildlife conflicts. Wildlife Research, 37, 623629.

Wilson, G. J., Delahay, R. J., de Leeuw, A. N. S., Spyvee, P. D. \& Handoll, D. (2003) Quantification of badger (Meles meles) sett activity as a method of predicting badger numbers. Journal of Zoology, 259, 49-56.

Wright, A., Fielding, A.H. \& Wheater, C.P. (2000) Predicting the distribution of Eurasian badger (Meles meles) setts over an urbanized landscape: A GIS approach. Photogrammetric Engineering \& Remote Sensing, 66, 423-428. 
523

524

525

526

527

528

529

530

531

532

533

534

535

536

537

538

539

540

541

542

543

544

545

546

547

548

549

550

551

552

553

554

555

556

557

558

559

560

561

562

563

564

565

566

567

568

\section{Supplementary material. Case studies}

The majority of cases involved a main sett affecting a single property, but ten cases affected multiple properties. In this latter situation, close co-operation between home owners was very important. In the few cases where neighbours were uncooperative, this slowed progress of the exclusion work, made work more challenging, usually due to issues of access, and appeared to increase stress experienced by the licensee (pers. obs.). The high level of cooperation between neighbours during the exclusion of two highly active main setts was, in our opinion, pivotal to their success. The following are brief descriptions of each case studied. All location names and personal identities are withheld.

1 - An eleven hole main sett covering four back gardens (present for at least twelve years) in the east of England was trapped resulting in the capture of nine badgers; two male adults, one breeding female, two male cubs and three female cubs. A partial exclusion began during autumn 2004 followed by partial excavation and badger proofing work, which continued for a month. Badgers were excluded from this garden, the perimeter of which was proofed, but animals retained access to parts of the sett via entrance holes in neighbouring gardens. A dispute over payment of exclusion costs between neighbours limited cooperation.

2 - Five badgers were trapped at a main sett in the east of England; three adults (one male and two females) and three cubs. Some of these animals also used the sett described in case 1 above. The licensed exclusion began in the autumn of 2005 and was successfully excluded and destroyed after the 21 day exclusion period. It was then proofed with chain link and badgers did not regain access.

3 - In summer 2004, a single badger excavated a hole next to an overgrown grave in a Midlands churchyard. Several graves were undermined and human bones were exposed on the spoil heap. An exclusion licence was granted and the badger was excluded from the hole following scrub clearance and fitting of a one-way gate. Several days before the exclusion the badger excavated two more holes, one at each of two nearby properties. One of these was excluded using a one-way gate and chain link under licence during the autumn. The badger moved to a culvert under a house (the only sett found) and was found dead four months later, caught in a snare at the entrance to the sett. Relevant authorities were informed.

4 - During spring to summer 2005 three adult females, an adult male, male cub and female cub were caught at a main sett in the east of England prior to exclusion work. During radio tracking we failed to identify alternative setts for these badgers. Exclusion work was not completed and the badgers remained within the sett.

5 - A three hole sett, known for thirty years, was present in a single east of England garden, but the tunnel system potentially spread under several gardens. During summer 2005 two adult females and two female cubs were trapped. The holes were gated under licence, but insufficient chain-link was laid. Badgers got back into the sett via an entrance 
569 hole that was not identified during the exclusion period. Two other setts were identified 570 nearby during daytime radio tracking and both tagged adults used these. One of these 571 was excluded under license and an attempt was made to exclude the other, but this failed. 572 A further outlier sett was found nearby soon after.

573

6 - A seven hole outlier sett along a grass railway embankment in the midlands, one of many along a short distance of embankment, was subject to a licensed exclusion using one-way gates and chain link in the summer of 2006. Three adult badgers, one male, a breeding female and a non- breeding female were trapped and tagged. The badgers made use of five other setts within their range. The tunnels extended under a private garden in which the patio had started to collapse. After failing to exclude the badgers the number of gates used and chain link deployed was extended along the embankment, but this also failed. Consequently, excavation was undertaken successfully and the private garden was proofed.

7 - A highly active four-hole main sett covered several private gardens in the south east. Four badgers (adult male, two adult females and a cub) were caught during the autumn of 2006. Three other setts were identified within the badgers' ranges during daytime radio tracking sessions. An exclusion attempt using one-way gates was unsuccessful so excavation was undertaken one month later. The garden perimeters were proofed against further interference from badgers.

$8 \& 9$ - A large private property in Greater London suffered the undermining of its outdoor swimming pool by a small but very active main sett from 2006 to 2008. An inactive twohole annex sett was located at the other end of the private garden. Understorey vegetation was removed back to the bare earth, but mature trees were left in situ. All entrance holes were gated and chain link was laid over the surface of the sett and surrounding area, but its edge was not buried in a trench. Approximately $50 \%$ of the garden area was covered in chain link. There was at least one other weak point in the chain link near an entrance hole adjacent to the swimming pool. Despite the presence of a sett a short distance away, and which the resident badgers occasionally used, they exploited the weak point in the chain link, gaining re-entry to the focal sett, which was not excluded during this attempt. The property was subsequently sold and the new owner received a licence to attempt a further exclusion two years after the initial attempt. By this time the sett had become much larger and more active. During this attempt, all vegetation was removed from the garden and chain link was laid over the whole area and was fixed to one-way gates installed over every entrance hole. During this disturbance badgers used up to three setts within their range. This time, the sett was successfully excluded and the garden was reinstated, at a total cost of approximately $£ 110,000$.

10 - This case involved a highly active main sett spread across four gardens in the south east during 2006. The problem centred on the undermining of a storm water drain and foul water sewer, but signs of subsidence of a patio and severe damage to lawns were also apparent. The licence applicant consulted with local homeowners and received the support and engagement of all those affected. The licensees engaged a professional consultant to manage the sett exclusion and landscape the gardens. In advance of the 
615 exclusion, all fences between affected properties were removed, all vegetation (excluding 616 a few very substantial trees) was removed down to the soil surface, leaving bare earth 617 across the whole site. A trench of approximately $1.5 \mathrm{~m}$ depth was dug around the site and galvanised chain link was laid over the ground surface and fed down into the bottom of the trench, which was then filled with hardcore rubble. One-way gates were fitted to every sett entrance hole, and the chain link was fixed around these. Once excluded, badgers continued to gain entrance to the sett by clawing at staples that had been left on the gates until they opened. We observed this behaviour using trail cameras positioned at sett entrances, and recorded badgers within the sett even when the licensee believed it had been vacated. After removal of the staples, the sett was rapidly vacated, and badgers moved to two other nearby setts within their range.

11 - The small outlier sett in this case, was undermining a driveway, which was subsiding, on a single property in the south east during 2006. The licensee intended to cover the ground with chain link and to fit one-way gates. However, before action was taken against the sett all detectable activity ceased. At the same time, we identified two collared badgers caught at this sett as having moved to an alternative sett. Consequently, the licensee simply covered the ground with chain link, without fitting one-way gates, and succeeded in keeping badgers out of the sett.

12 - A moderately active but reasonably large (five entrance holes) outlier sett was causing damage to a garden in the north west, including subsidence of a garden wall during 2007. No vegetation clearance was undertaken, and no chain link was initially used, but one-way gates were fitted to each hole. Badgers gained re-entry to the sett by digging around the gates, so the licensee fitted chain link around and fixed to each gate, but only covering approximately $20 \%$ of the vulnerable area. Nevertheless, the exclusion was successful and badgers took up residence in a sett a few hundred metres away.

$13 \& 14$ - This active main sett undermined land immediately adjacent to a fire exit of a council-run property in the midlands. During 2007 an artificial sett was built on neighbouring land, although the diameter of pipes used to construct the tunnels was inadequate, and were positioned so that it was possible for rain water to collect within the sett. Some understorey vegetation was cleared, but many trees and some bushes remained. Chain link was laid over the surface of the sett and immediately surrounding area, but was not buried into a trench at its edge. One-way gates were fitted to all entrance holes, but badgers dug under the chain link and around the gates, and were not excluded during 2007. We saw no evidence of the artificial sett being used by badgers. In 2008 , a new contractor was employed to build a fence around the sett. The fence was made of galvanised chain link, which was buried into the ground. A one-way gate was fitted into the fence. Badgers were evicted from the sett, which was subsequently destroyed.

15 - This sett in the south east was under a substantial temporary school building, making sett surveying challenging. Vegetation removal was not necessary, and chain link was installed around the base of the building, with one-way gates fitted into it, producing an effect not too dissimilar to the fence described above. However, a single annex hole 
660 adjacent to the building was gated, without chain link surrounding it. Badgers were

662

663

664

665

666

667

668

669

670

671

672

673

674

675

676

677

678

679

680

681

682

683

684

685

686

687

688

689

690

691

692

693

694

695

696

697

698

699

700

701

702

703

704 successfully evicted from the sett during 2007 , and took up residence in a nearby sett.

16 - This case involved a large, active main sett spread across three gardens in the east of England during 2007. The licensee's home had been devalued due to the sett's proximity to his house and the entrance holes heading in the direction of it. One of the affected neighbours was supportive of the licence application, but the other was not. This neighbour's garden contained the majority of the sett, and the home owner routinely fed badgers in her garden and welcomed their presence. After much debate, this home owner agreed to the temporary exclusion of badgers from the sett. Vegetation was partially cleared to facilitate fitting of one-way gates, but no chain link was used. In the other two gardens vegetation was cleared and the sett was excavated. After successful exclusion of the badgers, during which time they moved off into one of three setts within their range, two of the gardens were proofed by destroying the portion of the sett on their land and infilling with concrete. The gates were removed from the third garden, and badgers were allowed to re-enter.

17 - A sports pavilion was undermined by a two-hole outlier sett in Greater London. A further two entrance holes were present within a neighbouring garden, but it could not be determined whether they were linked to the former holes. Vegetation, except for mature trees, was removed from the area surrounding the former holes and chain link was laid on the ground, without burying the edge into a trench. One way gates were fitted over the two holes and fixed to the chain link. One of the holes in the garden was soft blocked, the other was inactive. After successful exclusion, the chain link was left in situ and covered over with earth.

18 - This large, active main sett was excavated into a bank at the edge of a private garden in the south east. The sett was causing the bank to erode, approximately one third of the garden having slipped away by the time of our survey. A little-used annex sett was present approximately $50 \mathrm{~m}$ along the bank. Problems arose due to the consultant requiring access to an uncooperative neighbour's garden, which took some time to resolve. Vegetation except mature trees was removed and chain link was laid over the main sett and surrounding area, with one-way gates fitted over each hole and fixed to the chain link. The chain link was not buried in a trench and no action was taken against the annex sett. After successful exclusion of the badgers, they moved to one of two setts a few hundred metres away along the same road. The sett was then destroyed during landscaping work to reinstate the bank and garden.

19 - This active main sett in the midlands was undermining a steep bank on the boundary of two gardens, and excavations under the upper garden had resulted in part of the lawn collapsing. Vegetation consisted of mature trees, which were left in situ. One-way gates were fitted to all entrance holes, and chain link was fitted around each gate, covering approximately $25 \%$ of the sett surface. Three other setts were present along the bank, and badgers took up residence in these after they were successfully excluded from the focal sett.

705 
706

707

708

709

710

711

712

713

714

715

716

717

718

719

720

721

722

723

724

725

726

727

728

729

730

731

732

733

734

735

736

737

738

739

740

741

742

743

744

745

746

747

748

749

750

751

20 - Two holes of this north west outlier sett opened on land belonging to a council run property with another in a private garden. The licensee gained agreement from the council to conduct a complete exclusion. Spoil was removed from outside all holes, but the sparse vegetation (a few bushes) was left in situ. Each hole was gated, and chain link was fitted to each gate, and around the surrounding area, but only protected approximately $20 \%$ of the vulnerable area of the garden. The badger (a mature female) was successfully excluded from the sett and took up residence in a nearby sett within her range. This sett had become more active during the current year than it had been before. It was believed by the local badger consultant that this female had been excluded during the previous year from an outlier sett undermining a temporary school building and within approximately $200 \mathrm{~m}$ of this case.

21 - The main problem caused by this midlands outlier sett was due to the volume of spoil making the garden unusable. A local badger enthusiast fitted one way gates to each of the two holes, but the door of these gates was manufactured from weld mesh, instead of the recommended plywood. No vegetation was removed, no chain link was fitted and the gates were not checked, and they soon became stuck open due to a build up of spoil. The exclusion failed.

22 - This main sett was undermining graves in a west country church yard, making gravestones unstable, and had made unusable an amenity grassland area belonging to a private courtyard development. Only after an exclusion had been attempted, which involved partial removal of vegetation and laying of chain link over approximately $65 \%$ of the vulnerable area and fitting of one-way gates to all visible holes, was a single hole annex sett discovered in a neighbouring garden. It was believed by the licensee that this annex sett was the cause of the exclusion failing.

23 - A large, active main sett in a large private garden in central England was causing a major A road to subside. The city council conducted the exclusion to protect the road. All vegetation except substantial mature trees was removed and chain link was laid over the entire area of the sett and some distance beyond, but it was not buried into a trench. All holes were gated. The badgers repeatedly found their way underneath the chain link and dug around the one-way gates to re-enter the sett. After several attempts to reinforce the chain link and gates, some of the badgers evacuated the sett. One took up residence in a nearby sett within its range, but another appeared to move into a neighbouring social group. This animal was radiotracked to a private garden approximately $500 \mathrm{~m}$ from the focal sett. The home owner had reported seeing a badger wearing a collar and suffering open wounds to its fore quarters. On investigation, we observed the free-living animal to within $10 \mathrm{~m}$, and concluded that the injuries were bite wounds to the shoulders.

24 - This large ( 30 hole), active main sett in the south had made a garden unusable since entrance holes were not only present within a bank of earth at the bottom of the garden, but were also present across approximately $50 \%$ of the lawn. Some vegetation was removed prior to exclusion, but mature bushes and trees were left in situ. All holes were gated, and chain link fixed to these covered approximately $80 \%$ of the vulnerable area. Despite having access to at least two outlier setts within their range, badgers penetrated

PeerJ reviewing PDF | (2016:03:9613:1:0:REVIEW 14 Sep 2016) 
752 the chain link, regaining entry to the sett, which was not successfully excluded within 31 753 days of the gates being closed.

754

755

756

757

758

759

760

761

762

763

764

765

766

767

768

769

770

771

772

773

774

775

776

777

778

779

780

781

782

783

784

785

786

787

788

789

790

791

792

793

794

795

796

797
25 - In a north west housing development of approximately 10-20 years of age, a private garden had been constructed from turf laid over builder's sand. An active, single hole outlier sett was undermining a patio, which was subsiding, and several tonnes of sand had been excavated by badgers, and deposited on the lawn. No vegetation was removed and no chain link was used, but a one-way gate was fitted over the entrance hole. Despite having access to another sett within its range, the badger re-gained entry to the focal sett by digging around the gate.

26 - An earth bank between a private housing development and a derelict club house in the midlands contained an active outlier sett, which undermined a private garden. The property next to the affected one also appeared to have entrance holes to a disused annex sett heading under its garden, but it was not possible to ascertain whether any structural damage was being caused. The sett entrances were all on the club's land, and the club agreed to allow the affected home owner to exclude the badgers. No vegetation was removed and no chain link was laid down, but by the time one-way gates had been installed over all entrance holes, the badgers had moved to a rural sett within their range. The exclusion was considered a success, and the sett was destroyed.

27 - A moderately active outlier sett in a midlands suburban woodland was undermining a retaining wall to a school that stood at the top of a cliff. After two attempts we trapped a single adult male badger, which had access to at least three other setts within its sizable range. Understorey vegetation was removed but mature trees, which were thought to maintain the integrity of the cliff, were left in situ. All entrance holes were gated and chain link was laid over approximately $90 \%$ of the vulnerable area and fixed to the gates, but the edge was not buried into a trench. Nevertheless, the sett was successfully excluded by 21 days of the gates being installed. Gates were subsequently removed and replaced with chain link, which remains in place.

28 - This moderately active outlier sett in the north east was undermining a garden shed and had made approximately $40 \%$ of the garden unusable due to the presence of entrance holes and spoil on the lawn and borders. A neighbouring garden contained two additional holes, but the involvement of this neighbour was not sought by the licensee. Consequently, the sett was partially excluded, with gates fitted to all holes in the focal garden. Chain link was fitted to and around the gates, covering approximately $25 \%$ of the vulnerable area. Little vegetation was present around the sett, and none was removed. Badgers were successfully excluded from the portion of the sett in the licensee's garden within 31 days of gate closure. However, the licensee later contacted us stating that badgers had re-gained entry into the sett.

29 - An active two-hole outlier sett in the south had made unusable approximately $40 \%$ of a private garden. Foraging by badgers in the lawned area had caused such significant damage that the home owner had laid artificial turf over the affected area in an attempt to prevent it. Vegetation removal was not necessary, and both holes were gated, with chain 
798 link fixed to these and over approximately $100 \%$ of the affected area. Badgers were 799 successfully excluded within 21 days of the gates being installed, and tagged badgers 800 took up residence in a main sett in a private garden within $100 \mathrm{~m}$ of this case.

801

802

30 - Three small terraced properties owned by a housing trust in the north west experienced considerable damage to a large proportion of their back gardens from 9 active holes associated with a main sett and a two-hole annexe. An adult male and a breeding female were trapped and collared, although the female shed her collar prior to release. All vegetation was removed from the gardens, all entrances were gated and $60 \%$ of the associated sett area covered with chain link on the surface. The housing trust also had an artificial sett constructed prior to the exclusion on an area of land at the end of the row of terraces. Despite these efforts the badgers regained access to the sett through weak points in the chain link where they were able to squeeze underneath it. More chain link was added and after several weeks of failing to exclude the badgers, an electric fence incorporating one-way gates was erected around the perimeter of the sett. This was also breached. After three months and several unsuccessful attempts to exclude the badgers the housing trust was granted a licence to excavate the sett to its destruction. By this time the male's collar had failed.

816

817

31 - An active 34 hole main sett in the north east on a slope adjoining a property, had enlarged subsequent to a successful exclusion at another sett close by. This led to the house owner becoming concerned that the structural integrity of his house was being weakened due to the sett undermining his property. A licence was granted to exclude the sett completely. However, the exclusion was not undertaken because the consultant was unsure on how to proceed and the quote $(£ 17,000)$ for the exclusion works was considered excessive by the property owner.

824

825

826

827

828

829

830

831

832

833

32 - An active 10-hole main sett covered three back gardens in a residential suburb in the west. Three animals were caught during late summer 2010; a female cub and two adult males. The two adults were fitted with GPS collars. The exclusion was undertaken by an ecological consultant with experience of badger exclusions. One-way gates were fitted and closed in the late summer. The area above the sett was cleared of vegetation, fences and a compost heap. Chain link was laid prior to gate closure. A tagged male breached the proofing on several occasions, and no alternative setts were identified within the badgers' range. Badgers were not excluded from the sett by the end of this study. 